\title{
Integrated Development of Rural Areas of Limited Potential for Social And Economic Growth
}

\author{
Plaksin V.N.* \\ Voronezh State Agrarian University named after Emperor \\ Peter the Great \\ Voronezh, Russia
}

\section{Volkova A.G.}

Russian Academy of national economy and public administration under the President of the Russian Federation Voronezh, Russia e-mail: ppivolk@mail.ru

\author{
Sabetova T.V. \\ Voronezh State Agrarian University named after Emperor \\ Peter the Great \\ Voronezh, Russia \\ e-mail: tsabetova@mail.ru
}

\author{
Plaksina P.V \\ Voronezh State Agrarian University named after Emperor \\ Peter the Great \\ Voronezh, Russia
}

Abstract - The subject of the study is the problem of the integrated development of rural areas of limited potential for socio-economic growth. The purpose of the work was the formation of a pool of risks arising from the uneven development of rural areas. The article systematizes the problem of managing the development of rural areas of limited potential for socioeconomic growth. The implementation of socio-economic development strategies for the rural areas of limited socioeconomic growth potential is a complex problem, determined by an aggregate set of goals and objectives, external factors, as well as specific characteristics of the region. The article specifies that the problems of managing the development of rural territories of limited potential for socio-economic growth at the current stage cannot be called sufficiently developed either from the point of view of economic and social efficiency or from the point of view of budgetary efficiency. The authors analyze the possible ways to overcome the problems of managing the integrated development of rural areas with limited potential for socio-economic growth. During the process of implementing the development strategies of the subregional territories of the Voronezh region till 2035 , regular monitoring and control of the degree of implementation of the planned action program and achievement of the planned targets should be provided. If necessary, the program of action should be adjusted based on data from participants in the implementation of the strategy. At the same time, it is necessary to ensure maximum transparency of the monitoring data on the intermediate results of the strategy implementation for the population and the expert community, which will contribute to expanding the possibilities of direct public control and citizen participation in the implementation of the strategy. The solution of problems within the framework of these areas allow optimization of goal and objective setting of the territorial development of rural territories of limited potential for socioeconomic growth.

Keywords - unevenness of territorial development, areas of limited potential for socio-economic growth, integrated development of rural areas.

\section{INTRODUCTION}

The uneven socio-economic development of territories for proves to be the key problem for a considerable number of countries. Its nuances are determined by such factors as the size of territorial entities, the availability, level of development and distribution of resources, climate, labor resources and their characteristics of reproduction, etc. To a certain degree, the unevenness of territorial development is characteristic of all states, regardless of the administrative territorial structure and level of development. As soon as the manifestations of unevenness can be controlled and remain moderate, they do not present any threat. Moreover, in some cases, unevenness is a blessing, since a higher level of development of one territorial entity also entails an increase in the levels of all others, especially with competent state regulation. However, if the level of socio-economic development and the standard of living of the population across territorial entities are significantly different, this gap is a serious problem for the state [1-3].

The vast majority of the territory of the Russian Federation is characterized by the fact that it has a pronounced rural character. At the same time, modern global challenges related to the supply of food for the growing world population, the fight against poverty, and the prevention of negative impacts on climate and water resources can only be resolved if sustainable rural development is achieved. Bearing this in mind, we see that the task of producing high-quality food products and raw materials for the food and processing industry comes to the fore. In this regard, programs on sustainable development of rural areas are becoming relevant, including promising areas of rural development and innovative solutions to environmental and social problems.

The current stage of socio-economic development of rural territories of the regions of the Russian Federation is characterized by low living standards for rural residents, reduction in labor resources, lack of qualified personnel, and does not contribute to the transition to these areas' sustainable development. In this regard, the urgent issue is the formation of effective state financial support for the sustainable development of rural areas with limited potential for socioeconomic growth. 
The problem of sustainable development was brought to life by the deep transformations that the market economy has undergone as a result of globalization in the past 15-20 years.

The concept of sustainable development appeared as a result of combining three main points of view: economic, social, and environmental. These are three closely interconnected and interdependent areas of a coherent whole. With this approach, organizations at the micro level and states at the macro level are considered as socio-ecologicaleconomic systems. Economic goals (profit, income) with this approach become secondary to the goal of maintaining the integrity of the environment. The transition to sustainable development requires fundamental changes, in the center of which is the environmentalization of all the key activities of mankind, of man himself, the change in his consciousness and the creation of a new "sustainable society" as a sphere of mind $[4,5]$. Such changes should not occur spontaneously, but purposefully, consciously, and one of the main mechanisms for controlling this process can be the moral, humane mind of a united humanity, using all possible socio-economic, political, and technical means.

The economic approach to sustainable development implies the optimal use of limited resources. The social component is aimed at maintaining social stability and cultural diversity on a global scale. For environmental safety, the sustainability of natural systems and their ability to self-repair and adapt to changing external conditions must be ensured.

The current socio-economic situation in the countryside ща Russia is characterized by accumulated problems that impede its transition to sustainable development. Insufficient qualities of living environment, limited opportunities for labor in rural areas, lower (compared with urban) income levels have to a large extent influenced the processes of outflow and degradation of labor resources and a decrease in the population of villages. In turn, this caused an increase in socio-economic imbalances in rural areas and the emergence of depressed rural areas, where many economic, social, and environmental problems are increasingly exacerbated.

It is worth noting that there are various approaches to understanding the essence of the category "sustainable development of rural territories" in modern economic literature.

The most widespread approach according to which the stability of rural areas is interpreted as a process that forms a positive trend in the development of territorial socio-economic system.

Note that at the legislative level, the concept of "sustainable development of rural territories" was first introduced in 2006 in Federal Law \#264-FZ "Concerning the development of agriculture". According to this document, sustainable development of rural territories means their stable socio-economic development, increase in agricultural production, increase of agricultural efficiency, achievement of full employment of the rural population, and increase of the living standard, rational land use.

The analysis of the existing approaches to determining the sustainable development of rural territories allows concluding that, in a broad sense, the sustainable development of rural territories is such a process that ensures the following conditions are met [6]:

(i) Fulfillment of national economic functions (production, demographic, spatial and communication, cultural, environmental, recreational);

(ii) Expanded reproduction of the population, rising levels, and improving the quality of life in rural areas;

(iii) Support of environmental balance in the biosphere.

It is worth emphasizing that the state plays a significant role in achieving the sustainability of the socio-economic development of rural areas with limited potential for socioeconomic growth. The key directions of state support for rural areas with limited potential for socio-economic growth in order to ensure their sustainable development are: diversification of the rural economy; creation of conditions for the resettlement of citizens in the countryside; improving the living conditions of citizens living in rural areas and providing housing for young families and young professionals; development of engineering and social infrastructure in rural areas, etc.

In recent years, under the influence of a qualitatively different level of development of productive forces, the introduction of innovations in all areas of life, IT and telecommunication systems, as well as the development of network forms of production organization, the problem of the integrated development of rural territories of limited potential for socio-economic growth has taken on new forms

\section{PROBLEM REVIEW}

The integrated development of rural areas is a targeted process for the long-term development of the industrial, economic, socio-demographic, cultural, environmental, recreational sectors of the village, forming a single system [7].

The integrated rural development program in the Russian Federation requires for large-scale financing. The formation of the mechanism for the integrated development of rural territories should be based on the active role of the state within each of the three subsystems (economic, social, and environmental), ensuring the solution of the formulated general tasks for the development of the region as a result of the application of an integrated interagency approach to achieving the planned target values and implementing program activities. Ensuring food security of the Russian Federation is possible only through sustainable integrated rural development.

Achieving this goal is to be carried out by employees in the agricultural sector. Therefore, the creation of effective jobs, the employment of young professionals, decent level of wages, comfortable living, and the development of social infrastructure are key areas of work for government bodies at all levels and for private business in the form of public-private partnerships. The design of a program for the integrated development of rural territories became objectively necessary.

The integrated rural development program will contribute to the implementation of the social principle associated with 
the reproduction of the living standards. In this case, social reproduction should be expanded, because it is important not only the physical increase in the rural population, but also as a change in the quality of life of the peasant community.

The strategic goals and objectives of the socio-economic development of rural territories are determined taking into consideration the solutions of the local government of the region, the availability of design estimates, questionnaire results and taking into account the views of experts. The goals of the strategic development of rural areas of limited potential for socio-economic growth are linked to the goals of the strategic development of the region as a whole [8].

The key problem in rural areas with limited potential for socio-economic growth is population decline, and the efforts of local governments are planned, first of all, to reduce the gap between them and the leading territories in terms of living standards. In this area, it is necessary to solve the problem of stabilizing the population of a territorial entity by reducing the outflow of the working population and creating comfortable and favorable conditions for active longevity of citizens. It is possible to suspend the outflow of the able-bodied population by implementing measures to create housing conditions for specialists living in rural areas, supporting young entrepreneurs, and creating leisure infrastructure.

It is possible to ensure the creation of comfortable and favorable conditions for active longevity of citizens by increasing the availability of medical services, and this would happen if the number of doctors is increased based on training in targeted recruitment and the provision of housing for healthcare employees [9].

Besides, local governments in rural areas with limited potential for socio-economic growth have the goals of providing the population of the region with quality housing, providing all residents of the district with quality drinking water, as well as a multi-faceted issue of improving the comfort of life of the population, which requires solving several problems such as construction and overhaul gas boiler houses, street lighting, reconstruction and overhaul of social facilities and places of mass recreation, ensuring the cleanliness of settlements and places of mass recreation for citizens.

To ensure the economic development of rural areas with limited potential for socio-economic growth, it is necessary to promote the creation of new enterprises and the development of small business in the agricultural sector. To ensure the polycentric development of rural areas with limited potential for socio-economic growth, it is necessary to solve the tasks of creating broadband and mobile Internet lines in the district's settlements, promoting the development of a network of intramunicipal roads, and organizing work to improve the quality of local roads and road infrastructure facilities

Rural territories with limited potential for socio-economic growth need to stabilize the population, first of all, to stop the outflow of youth. For this purpose, it is necessary to concentrate efforts on such projects that would increase the comfort of living of the able-bodied population [10]. The key projects should address housing and leisure issues.
Considering the rural infrastructure in the areas with limited potential for socio-economic growth, increased attention should be paid to projects that will solve longstanding problems with water quality and road network quality.

The well-being of rural areas with limited potential for socio-economic growth directly depends on the implementation of investment projects. Attracting investment will allow territorial entity to develop steadily.

\section{ANALYSIS}

The risk object (development targets for rural areas with limited potential for socio-economic growth) is exposed to a number of factors, the main among which are the following:

\section{A. Geopolitical factors}

The growth of geopolitical uncertainty in recent years negatively affects investment attractiveness and the development rate of the Russian economy. The preservation of the sanctions regime against Russia is an important source of deterrence of investment potential.

Among the other consequences of sanctions and countersanctions is the release of market niches for Russian producers and the drop in the exchange rate of the ruble. The reduced availability of cheap foreign credit resources is an important factor determining the risk of securing financing program. At the same time, it is difficult to assess how much this damage exceeds the possible benefits associated with ensuring stable domestic demand for import-substituting products and reducing competition for Russian economic entities.

We can definitely state that this factor has a much more significant effect on small and medium-sized businesses, for which access to foreign credit markets is not significant. The positive effects of emerging market preferences for Russian enterprises on the domestic market, obviously, will not be limited to the period of the sanctions regime, and will provide them with additional profit for many years. It is small and medium-sized businesses that are the basis for the development of the national economy, which ensures the sustainability of economic growth, reduces the negative effect of the cyclical nature of economic development, and helps diversify the economy of the region and the state as a whole.

In relation to this and similar ambiguous geopolitical trends, it is advisable to mitigate possible negative consequences, as well as use the current situation with the maximum benefit for the socio-economic development of the region. For example, to fill the deficit in credit resources at the federal level, priority projects are already being financed at a reduced credit rate.

At the same time, the authorities can not only increase the share of Russian producers in the domestic market, but also help to expand the benefits for Russian exporters in foreign markets. The measures taken today to simplify customs rules for small and medium-sized businesses will significantly contribute to the export potential of Russian manufacturers.

These changes in customs policy are especially relevant in conjunction with the natural advantages of this situation for 
exporters related to the ruble exchange rate that is advantageous to them. It is necessary to provide support for this initiative of the Federal Customs Service at the level of the Voronezh region.

\section{B. Macroeconomic factors}

Due to the unstable economic situation and the drop in GDP, investment inflows have been declining in recent years. Foreign investment is one of the important sources of economic development [11]. However, despite a number of advantages associated with an increase in direct investment, accelerating the pace of economic development, and improving the country's balance of payments, foreign investment entails the repatriation of profits, less control over the activities of enterprises, and, in the absence of additional obligations of investors, can lead to a deterioration in the structure of production and economies, adversely affect employment, etc.

In addition to improving the investment climate and increasing the size of foreign direct investment, measures are also important to create preferences for those investments that are related to high-tech industries, increasing the level of employment and skills of the workforce, long-term investments in the real sector of the economy, introducing the latest foreign technologies, not yet represented in Russia. Thus, not only an increase in the quantity, but also improvement in the quality of investments will be ensured.

Another trend in recent years is the increase in social burden and the reduction of federal budget expenditures, which leads to a change in its structure and the reduction in the share of investments. In the context of existing problems with the pumping up the budgets of all levels, one of the key risks of implementing the strategy of the territorial development of the municipality with an agricultural focus is the risk of underfunding [12]. It threatens not only the implementation of the projects laid down in the program, but also the achievement of the target indicators of the strategy.

An important problem is also the decrease in the solvency of the population. The low solvency of Russians determines the corresponding levels of consumption and the volume of the domestic market. This factor made a significant contribution to the decline in GDP, however, the probability of a further decline in real incomes and the solvency of the population during the implementation of the strategy seems to be rather low according to Russian and foreign forecasts.

\section{Social factors}

The all-Russian trend is the expected decrease in the total number of births in subsequent years. Besides, the increase in life expectancy of Russians determines the aging process. The reduction in the share of the working population in the medium term will help stabilize or even reduce unemployment. However, such changes can hardly be considered positive, since the qualitative characteristics of the labor force become more important and determine a higher level of social risk [13].

The mentioned demographic trends determine the importance of competent regional policy on the comprehensive support of fertility, improving the quality of education and health care, as well as labor migration.

\section{Innovation factors}

The most important factor in economic development in the modern world is innovation. Accelerated technological development leads to increase in the competition intensity and contributes to increase uncertainty at all levels of economic activity [14].

The increasing role of innovation entails an increase in the risks associated with the planning and effectiveness of innovative projects, provision of sufficient funding, as well as increasing requirements for the qualification of the workingage population. In combination with the existing demographic trends, manifested in the decrease in the general supply in the labor market, these risks are extremely significant both at the regional and national levels. Since the consequences of this type of risk can be extremely significant, the development, implementation, and financing of programs to increase the labor potential of the region should have the highest priority.

It is necessary to provide maximum support for advanced innovative developments and projects that contribute to increasing the competitiveness of the region. The growing competition of Russian regions for human resources forces us to pay special attention to creating the conditions for maintaining and attracting highly qualified specialists, and ensuring the competitiveness of the regional labor market.

The preservation of the sanctions regime, among other things, limits the access of Russian companies to certain foreign technologies that have no analogues in Russia. This is an additional incentive to support import substitution in order to reduce dependence on foreign technologies and reduce innovation risks.

Factor risk analysis, despite its prevalence and visibility, is a very difficult task, as the identification of risk factors is not its result and ultimate goal, although it represents the information basis of risk analysis [15]. Based on the description of the totality of risk factors for the strategy implementation, it is necessary to interpret the possible influence of the identified factors on the results and predict the complex consequences of the influence of one or another factor.

Unlike some types of pure risks (production, environmental, etc.), most risks of economic activity entail a number of ambiguous consequences. The task of the control subject in this case is not to avoid or minimize risks, as is usually assumed, but to describe the possible consequences of the risk as accurately as possible and to develop an adequate program to respond to restrictions and opportunities that have arisen as a result of changes.

\section{CONCLUSION}

The configuration of the socio-economic space of the Russian Federation can be described as unbalanced and heterogeneous. This is a significant deterrent to moving towards sustainable development. The growing unevenness of development of rural areas with limited potential for socioeconomic growth can jeopardize both the integrity and 
security of the country. The participation of the state in the process of regulating territorial development is required in order to prevent the negative consequences of unevenness.

In the attempts to correct the established imbalance that has developed over many years, it is quite expectable that the process of correction will also require a lot of time. The longer the complexity of development was ignored or even intentionally maintained, the longer the reverse process will take, as the spatial structure of the economy, as a rule, is characterized by a rather high degree of inertia. It is important in this process of eliminating the negative consequences to transfer enough authority to the rural territories themselves with limited potential for socio-economic growth, delegating to them the tasks of equalization.

In our opinion, the following measures are necessary to achieve the goal of ensuring sustainable development of rural areas with limited potential for socio-economic growth:

1) The development of cooperation and integration of small businesses, which requires maintaining a comprehensive interest in these processes from existing and potential entrepreneurs, the population of rural areas, as well as state authorities. This will solve a wide range of problems facing it. The development of the cooperative movement can become widespread and increase the well-being of rural residents.

2) The increase in entrepreneurial activity and the development of business, including alternative business, will allow the population of rural areas to receive additional income, government bodies to solve a number of problems: employment of the population and an increase in the tax base, attraction of borrowed capital in the creation and development of infrastructure.

3) Providing information and consulting support for rural development, and training for the villagers.

4) The development of rural infrastructure is one of the key problems in the development of the rural community and the designing of a set of measures of an economic, legal, and administrative nature. It may improve the quality of life in rural areas.

5) Improving agricultural production, which is especially important for areas with a high share of this type of economic activity in the structure of the gross product and having a significant impact on the formation of the revenue of the municipality budget.

Implementation of the development directions for the rural areas with limited potential for socio-economic growth proposed above will make it possible to achieve high economic indicators, ensure the country's food security, and increase the well-being of citizens.

\section{References}

[1] T. Leon, V. Liern, B. Perez-Gladish, "A multicriteria assessment model for countries' degree of preparedness for successful impact investing", Management decisions, December 2019

[2] Z. Zang, K. Tan, X. Yang, "Social and economic benefits of doctors on online health-care platforms based on the social capital theory", Nankai Busin. Rev. Int., vol. 11, iss. 1, pp. 121-140, 2019.

[3] M. Wagner, "Global governance in new public environmental management: An international and intertemporal comparison of voluntary standards' impacts", Busin. Strategy and The Environment, vol. 29, iss. 3, pp. 1056-1073, 2019.

[4] Z. Liu, X. Li, X. Peng, "Green or nongreen innovation? Different strategic preferences among subsidized enterprises with different ownership types", J. of Cleaner Product., vol. 245, art. 118786, 2020.

[5] L.C. Vieira, S. Serrao-Neumann, M. Howes, "Local Action with a Global Vision: The Transformative Potential of Food Social Enterprises in Australia", Sustainability, vol. 11, iss. 23, art. no. 6756, 2019.

[6] R. Tariq, D. Jaramillo, D.T. Dyjack, "Environmental Health Systems and Delivery of Services in the United States and Its Territories", J. of Environmental Health, vol. 82, iss. 5, pp. 22-27, 2019.

[7] J. Mendoza Jimenez, C. Roman Cervantes, M. Hernandez Lopez, "Social Economy and Public Procurement: the reserved procurements tool", Ciriec-Espana Revista De Econ. Publica Soc. Y Cooperativa, vol. 97, pp. 213-244, 2019.

[8] S. Ackerman, "Consistency of survey opinions and external data", Computat. Statist., vol. 34, iss. 4, spec. iss. SI, pp. 1489-1509.

[9] Yixiao Zhou, Rod Tyers, "Automation and inequality in China", vol. 58 [Proc. conf. 29th Annual Int. Conf. of the Chinese-Economics-SocietyAustralia (CESA)] Univ Western Australia, Perth, AUSTRALIA, JUL 12-14, 2017. China Econ. Rev.

[10] T.S. Sabetova, N.M. Shevtsova, Interconnection of the level of human capital development and the level of the socio-economic development of a region, Monograph. Voronezh: Kvarta, 2018, 186 p.

[11] N. Krishnan, S. Olivieri, R. Ramadan, "Estimating the Welfare Costs of Reforming the Iraq Public Distribution System: A Mixed Demand Approach", J. of Development Studies, vol. 55, spec. iss. SI Annex 1, pp. $91-106$

[12] A.G. Volkova, "The Problem of Dividing The Power of Authorities of Different Levels In The Implementation of the Budgetary Policy", pp. 44-49, 2016 [Proc. conf.] Voronezg,

[13] C. Schroeder, C. Bartels, M.M. Grabka et al., "A Novel Sampling Strategy for Surveying High Net-Worth Individuals-A Pretest Application Using the Socio-Economic Panel", Rev. of Income and Wealth, 2019, December.

[14] J.V. Narolina, T.V.Sabetova, N.V. Shabutskaya, N.V. Gryshchenko, "The Influence of Innovative Development on Economic Security of the Region”, Bull. of VSUET, vol. 81, no 1(79), pp. 457-463, 2019.

[15] N.V. Slinkova, A.G. Volkova, T.V. Sabetova, "Risks Of The Territorial Development Strategy Of The Agrarian Oriented Municipality", Russ. J. of Agricult. and Socio-Econ. Sci., vol. 5, no. 65, pp. 60-66, 2017. DOI: 10.18551/rjoas.2017-05.09 